\title{
Vitamin A Status of Neonates with Bronchopulmonary Dysplasia
}

\author{
JAYANT P. SHENAI, FRANK CHYTIL, AND MILDRED T. STAHLMAN \\ Departments of Pediatrics [J.P.S., M.T.S.] and Biochemistry [F.C.], Vanderbilt University Medical Center, \\ Nashville, Tennessee 37232
}

\begin{abstract}
We prospectively assessed and compared the vitamin A status of two groups of preterm neonates ( $<1500$ g birth weight, $<32$ wk gestation), one who developed clinical and radiographic evidence of bronchopulmonary dysplasia $(B P D)(n=10)$, and the other (control) who developed no significant lung disease $(n=8)$. The infants with BPD in this study required prolonged mechanical ventilation and supplemental $\mathrm{O}_{2}$ therapy, and had a higher incidence of cardiorespiratory complications when compared to controls. Their mean plasma vitamin A concentrations were significantly lower than those of controls at four sampling times in the 1st postnatal month. In contrast to the controls, infants with BPD showed a substantial decline in their plasma vitamin A concentrations from the initial values, and a high percentage of individual values of plasma vitamin $A$ concentration in these infants were $<10 \mu \mathrm{g} / \mathrm{dl}$ during the 8-wk postnatal period of observation. Delayed establishment of gastrointestinal feeding and a lower vitamin $A$ intake in these infants relative to controls may have accounted for this decline. Our data show that preterm neonates who develop BPD have suboptimal plasma vitamin A concentrations for extended periods of time postnatally. We speculate that the necrotizing bronchiolitis and squamous metaplasia of conducting airways associated with vitamin $\mathbf{A}$ deficiency could influence the orderly repair of lung injury in susceptible neonates who are mechanically ventilated and could contribute to the pathophysiology of BPD in these infants. Further studies are needed to determine whether more efficient management of these neonates with regard to their vitamin A nutrition and early achievement of vitamin A sufficiency could result in a decrease in the incidence and severity of BPD. (Pediatr Res 19: 185-189, 1985)
\end{abstract}

\section{Abbreviations}

BPD, bronchopulmonary dysplasia

HMD, hyaline membrane disease

PDA, patent ductus arteriosus

RBP, retinol-binding protein

Vitamin A (retinol) influences the orderly growth and differentiation of epithelial cells. Severe vitamin A deficiency results in changes in the tracheobronchial tree that include basal cell

Received June 25, 1984; accepted October 2, 1984.

Address for correspondence and reprint requests Jayant P. Shenai, M.D., Department of Pediatrics, Vanderbilt University Medical Center, Nashville, TN 37232.

This research was supported by Research Grants (SCOR HL 14214, HL 15341, and HD 09195) from the National Institutes of Health. proliferation leading to necrosis of lining epithelium, followed by squamous metaplasia $(1,2)$. Necrotizing bronchiolitis and squamous metaplasia of the epithelium of conducting airways are frequently seen in infants dying with BPD, following ventilatory management of conditions such as HMD $(3,4)$. The pathophysiologic consequences of these changes would include a lack of the mucociliary transport mechanism for removal of foreign material, including pathogenic organisms $(5,6)$, and abnormalities of water transport across the trachea (7). These abnormalities may influence orderly repair of lung injury and contribute to the pathophysiology of BPD in preterm infants.

The plasma concentrations of vitamin A and RBP of preterm infants at birth are low when compared to those of term neonates (8-10). Their liver vitamin A reserves are also low, suggesting that their potential ability to offset an inadequate vitamin $\mathrm{A}$ intake is poor (11). The provision of vitamin A to sick neonates who require protracted mechanical ventilation may be difficult by the oral route and the infants who are maintained exclusively on intravenous nutrition may be compromised by substantial losses of the vitamin by its adsorption to intravenous tubing and by its photodegradation (12). These observations prompted us to examine the role of vitamin A deficiency in the development of BPD in susceptible preterm neonates. This study was designed to prospectively assess and compare the vitamin A status of two groups of preterm neonates, one who developed clinical and radiographic evidence of $\mathrm{BPD}$, and the other who developed no significant lung disease.

\section{MATERIALS AND METHODS}

Subjects. Ten infants who developed BPD were the subjects of the study. These infants were selected prospectively by using criteria proposed by Bancalari et al. (13) to identify infants at risk for development of BPD. These criteria were birth weight $<1500 \mathrm{~g}$, gestational age $<32 \mathrm{wk}$, and requirement for mechanical ventilation during the 1 st wk of life for a period of at least $72 \mathrm{~h}$. HMD was the cause of respiratory insufficiency in $6 / 10$ infants; the remainder had pulmonary edema as the initial diagnosis. The diagnosis of BPD was based on clinical criteria and the need for protracted mechanical ventilation and high inspired $\mathrm{O}_{2}$ concentrations $\left(\mathrm{FIO}_{2} \geqslant 0.3\right)$ at 28 days postnatal age (14). All infants showed chest radiographic features of BPD as described by Edwards (15).

Eight control infants of similar birth weight and gestation were enrolled concurrently in the study. These infants had mild cardiorespiratory abnormalities that were resolved by 7 days postnatal age. None developed progressive lung disease as evidenced by a lack of a need for supplemental $\mathrm{O}_{2}$ or mechanical ventilation at 28 days postnatal age. Their chest radiographs were normal at that time.

The two groups of infants did not differ statistically with respect to mean gestational age or birth weight (Table 1). The 
Table 1. Clinical characteristics of infants*

\begin{tabular}{lcc}
\hline \multicolumn{1}{c}{ Group } & $\begin{array}{c}\text { BPD } \\
(n=10)\end{array}$ & $\begin{array}{c}\text { Control } \\
(n=8)\end{array}$ \\
\hline Sex (male/female) & $6 / 4$ & $5 / 3$ \\
Race (white/ & $8 / 2$ & $6 / 2$ \\
black) & & \\
Gestation (wk) $\dagger$ & $28.1 \pm 1.5$ & $29.4 \pm 1.2$ \\
Birthweight (g) $\dagger$ & $946 \pm 218$ & $1138 \pm 150$ \\
OFC (cm) $\dagger$ & $25.7 \pm 1.6$ & $26.7 \pm 1.1$
\end{tabular}

* Abbreviation: OFC, occipitofrontal circumference.

$\uparrow$ Mean $\pm \mathrm{SD}$; no significant differences were noted between groups.

gestational age ranged from 28 to 31 wk in $8 / 10$ infants from the BPD group and $8 / 8$ infants from the control group. Their birth weights ranged from 850 to $1320 \mathrm{~g}$. Two infants from the BPD group were 26 wk gestational age and weighed 580 and 640 $\mathrm{g}$ at birth, respectively. The clinical course in these two infants and their nutritional vitamin $\mathrm{A}$ intake and plasma vitamin $\mathrm{A}$ concentrations were similar to those of other infants in the BPD group. The distribution of infants with regard to sex and race was similar in the two groups. None of the infants had congenital anomalies or evidence of intrauterine growth retardation.

Procedures. Informed consent was obtained from the parents of each infant. The study was approved by the Committee for the Protection of Human Subjects-Health Sciences of the Institutional Review Board of Vanderbilt University. The neonatal intensive care unit staff was responsible for all decisions related to diagnostic and therapeutic aspects of clinical management of these infants. The general management of infants with respiratory problems in this unit has been previously described (16). Baby Bird Pediatric Ventilators were used throughout the study period. Clinical monitoring consisted of assessment of ventilatory status, cardiorespiratory status, growth, nutritional intake, medications, and complications.

All infants were maintained exclusively on intravenous glucose in the early postnatal period. Parenteral nutrition was started within the 1st wk of life. The vitamins in the parenteral solution were derived from the addition of $2.0 \mathrm{ml}$ of an aqueous multivitamin preparation (MVI, USV Pharmaceutical) to 1.0 liter of the solution at the time of preparation. The vitamin A concentration of the parenteral solution was $400 \mathrm{IU} / \mathrm{dl}$. Oral feedings were begun in all infants as soon as their clinical condition permitted. Continuous transpyloric infusion was the preferred mode of feeding for ventilator-dependent infants. Intermittent orogastric gavage was the choice for ventilator-free infants. Infants were fed either human milk or infant formula. The vitamin A concentration of the milk was 240-550 IU/dl. Approximately $1.0 \mathrm{ml}$ of an oral multivitamin preparation (Poly-Vi-Sol, Mead Johnson) was added to the diet from 5 th day of oral feeding. The oral supplemental vitamin A intake was $1500 \mathrm{IU} /$ day.

Approximately $0.7 \mathrm{ml}$ of blood was drawn from each infant by venous puncture at $4,14,21$, and 28 days postnatal age. Blood samples were drawn into heparinized collection vessels at a specific time of the day in all infants. Plasma was separated from each sample by centrifugation and stored at $-20^{\circ} \mathrm{C}$ prior to the analysis. Plasma vitamin A concentration was determined in duplicate by the fluorometric method described by Thompson et al. (17). Additional blood samples for plasma vitamin A determination were drawn at $35,42,49$, and 56 days postnatal age from infants in the BPD group. Early discharge to other medical facilities precluded blood sampling of control infants at these postnatal ages.

Statistical analysis. Hewlett-Packard HP-55 programmable calculator was used for data analysis. Student's unpaired $t$ test and Wilcoxon nonparametric test were used to determine the significance of differences between mean values.

\section{RESULTS}

Clinical course. Infants with BPD required supplemental $\mathrm{O}_{2}$ therapy and mechanical ventilation for significantly longer periods of time than the control infants (Table 2). In infants with BPD, the $\mathrm{FIO}_{2}$ requirement was $\geqslant 0.3$ for approximately $73 \%$ of the duration of $\mathrm{O}_{2}$ therapy, and the ventilator rate was $\geqslant 30 / \mathrm{min}$ for approximately $38 \%$ of the duration of mechanical ventilation. The maximal peak inspiratory pressure was $20-32 \mathrm{~cm} \mathrm{H}_{2} \mathrm{O}$, and the maximal peak end-expiratory pressure was $4-8 \mathrm{~cm} \mathrm{H}_{2} \mathrm{O}$. The corresponding pressures in the control infants were 12-20 and $3-4 \mathrm{~cm} \mathrm{H} \mathrm{H}_{2} \mathrm{O}$, respectively. In the period following withdrawal of mechanical ventilation, infants with $B P D$ required continuous positive airway pressure $\left(4-8 \mathrm{~cm} \mathrm{H}_{2} \mathrm{O}\right)$ by nasal route for a significantly longer period of time than the control infants.

Infants with BPD had a higher incidence of cardiorespiratory complications than the control infants (Table 3). Pulmonary air dissection was diagnosed by radiographic criteria. The protocol

Table 2. Ventilatory requirements of infants*

\begin{tabular}{cccc}
\hline Group & BPD & Control & $p$ \\
\hline $\mathrm{O}_{2}$ therapy (days) $\dagger$ & & & \\
Total duration & $56.4 \pm 21.1$ & $10.4 \pm 9.3$ & $<0.001$ \\
& $(32-97)$ & $(1-28)$ & \\
$\mathrm{FIO}_{2} \geqslant 0.3$ & $41.2 \pm 20.3$ & $3.0 \pm 2.4$ & $<0.001$ \\
& $(15-84)$ & $(1-7)$ & \\
IPPV (days) $\dagger$ & & & \\
Total duration & $40.0 \pm 18.9$ & $3.9 \pm 2.7$ & $<0.001$ \\
& $(18-75)$ & $(0-7)$ & \\
VR $\leqslant 10 /$ min & $2.3 \pm 3.3$ & $0.5 \pm 0.8$ & $\mathrm{NS}$ \\
& $(0-10)$ & $(0-2)$ & \\
VR $11-29 /$ min & $22.5 \pm 14.5$ & $2.5 \pm 2.2$ & $<0.01$ \\
& $(6-47)$ & $(0-6)$ & \\
VR $\geqslant 30 /$ min & $15.2 \pm 9.8$ & $1.6 \pm 1.8$ & $<0.01$ \\
& $(5-36)$ & $(0-4)$ & \\
CPAP (days) $\dagger$ & & & \\
Duration & $8.0 \pm 7.4$ & $1.3 \pm 1.5$ & $<0.05$ \\
& $(0-23)$ & $(0-4)$ & \\
\hline
\end{tabular}

* Abbreviations: IPPV, intermittent positive pressure ventilation; VR, ventilator rate (breaths/min); CPAP, continuous positive airway pressure (by nasal route).

$\dagger$ Values are mean \pm SD (range).

Table 3. Cardiorespiratory complications*

\begin{tabular}{clc}
\hline Group & BPD & Control \\
\hline Pulmonary air dissection & $5 / 10$ & $0 / 8$ \\
PIE & $5 / 5$ & 0 \\
Pneumothorax & $2 / 5$ & 0 \\
sPDA & $9 / 10$ & $2 / 8$ \\
Medical treatment & $8 / 9$ & $2 / 2$ \\
Surgical treatment & $1 / 9$ & $0 / 2$ \\
Sepsis & & \\
No. of episodes & & \\
per infant $\dagger$ & $2.3 \pm 0.7$ & $1.1 \pm 0.6$ \\
Antimicrobial & $37.1 \pm 21.7$ & $11.1 \pm 6.8$ \\
treatment (days) $\ddagger$ & & \\
Airway infection§ & $8 / 10$ & $0 / 8$ \\
\hline
\end{tabular}

* Abbreviations: PIE, pulmonary interstitial emphysema; sPDA, symptomatic patent ductus arteriosus.

$\dagger$ Clinically suspected sepsis with or without confirmation by culture. Values (mean $\pm \mathrm{SD}$ ) were significantly different between groups $(p<$ 0.01 ).

$\ddagger$ Cumulative antimicrobial treatment. Values (mean \pm SD) were significantly different between groups $(p<0.01)$.

$\S$ Confirmed by cultures of airway secretions. 


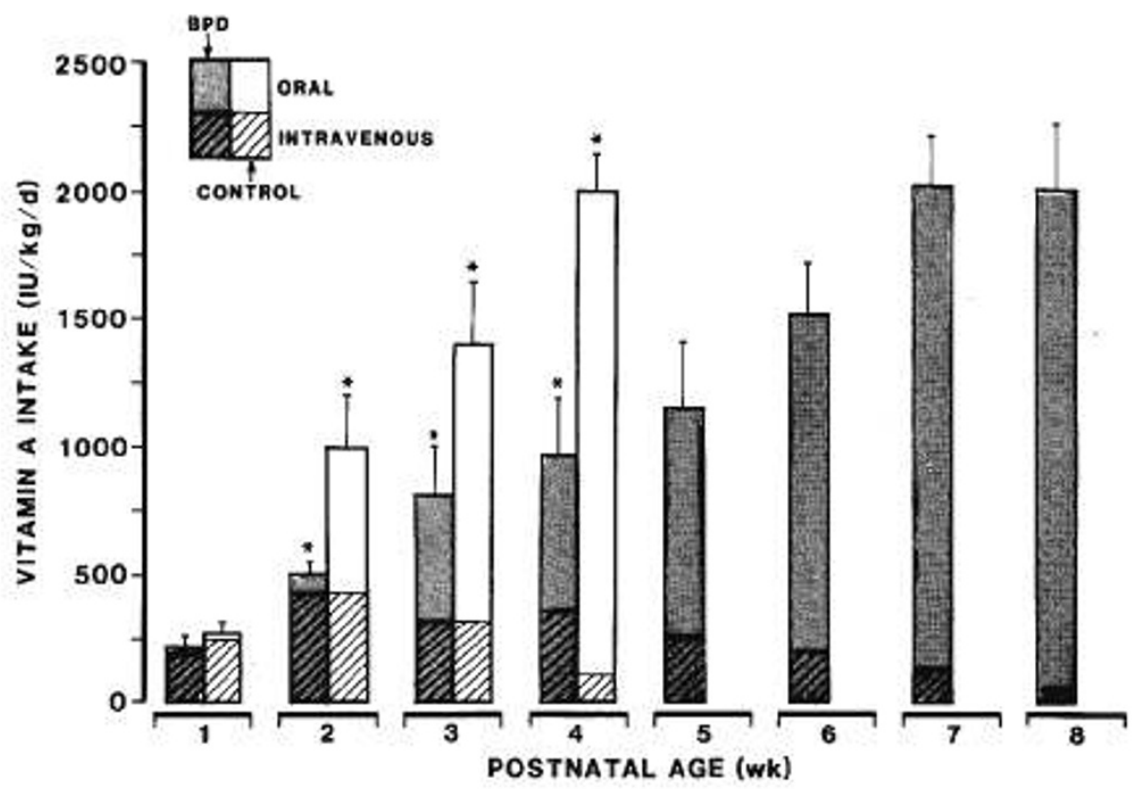

Fig. 1. Average total (oral + intravenous) daily vitamin A intake (mean \pm SEM). Asterisk denotes significant difference between groups $(p<$ $0.05)$.

Table 4. Plasma vitamin A concentrations of infants

\begin{tabular}{lcccc}
\hline & \multicolumn{4}{c}{ Postnatal age (days) } \\
\cline { 2 - 5 } Group & 4 & 14 & 21 & 28 \\
\hline BPD* $^{*}$ & $13.3 \pm 6.0$ & $12.0 \pm 3.9$ & $10.6 \pm 6.3$ & $10.3 \pm 8.7$ \\
Control $^{*}$ & $23.3 \pm 13.1$ & $29.3 \pm 9.9$ & $18.1 \pm 8.3$ & $18.9 \pm 6.7$ \\
$p$ & $<0.05$ & $<0.001$ & $<0.05$ & $<0.05$ \\
\hline \multicolumn{4}{c}{ Postnatal age (days) } \\
\cline { 2 - 5 } & 35 & 42 & 49 & 56 \\
\hline BPD* $^{*}$ & $11.4 \pm 9.7$ & $14.8 \pm 8.5$ & $17.2 \pm 8.0$ & $19.5 \pm 10.3$
\end{tabular}

$*$ Values $(\mu \mathrm{g} / \mathrm{dl})$ are mean $\pm \mathrm{SD}$.

for diagnosis and management of symptomatic PDA has been described previously (18). The medical management of this complication included one to four doses of intravenous indomethacin $(0.2 \mathrm{mg} / \mathrm{kg} / \mathrm{dose})$. One infant from the BPD group underwent surgical ligation of the ductus following failure of response to medical management. Secondary airway infection confirmed by cultures of airway secretions occurred only in infants from the BPD group. The prevalent microorganisms included Coagulase-negative Staphylococcus, Enterococcus, and Pseudomonas aeruginosa.

Nutritional intake. The mean $( \pm \mathrm{SD})$ age at commencement of oral feeding was $22.4 \pm 15.3$ days in infants with BPD and 8.1 \pm 2.6 days in control infants $(p<0.02)$. The mean $( \pm \mathrm{SD})$ age at commencement of oral vitamin A supplementation was $29.8 \pm$ 14.5 days in infants with BPD and $15.5 \pm 5.0$ days in control infants $(p<0.02)$. The average daily vitamin $A$ intake in infants is shown in Figure 1. In wk 2 through 4 , the total intake of vitamin A was significantly lower in infants with $\operatorname{BPD}(p<0.05)$ due largely to a difference in the oral intake of vitamin A. The maximum vitamin A intake in infants with established oral feeding ranged from 2020 to $2370 \mathrm{IU} / \mathrm{kg} /$ day in both groups. In infants with BPD, a mean vitamin A intake $>2000 \mathrm{IU} / \mathrm{kg} /$ day was achieved in the 7 th postnatal wk in comparison to the 4 th postnatal wk in control infants.

Plasma vitamin $A$. The mean plasma vitamin A concentrations were significantly lower in infants with BPD than in control infants at 4, 14, 21, and 28 days postnatal age (Table 4). During this period, a higher percentage of individual values of plasma vitamin A concentration was $<10 \mu \mathrm{g} / \mathrm{dl}$ in infants with BPD ( $45 \%$ of all values) than in control infants ( $6 \%$ of all values). All infants with BPD showed a progressive fall in their plasma vitamin A concentrations. The percent decrease in these concentrations from the initial values exceeded $40 \%$ in $7 / 10$ infants. The lowest concentrations in these infants ranged from zero (below detection) to $12.3 \mu \mathrm{g} / \mathrm{dl}$. In contrast, in $4 / 8$ control infants, the plasma vitamin A concentrations showed a progressive increase from the initial values, while in the remainder, the percent decrease in these concentrations from the initial values was less than $40 \%$. Although a gradual rise in plasma vitamin A concentrations was seen in a majority of infants with BPD during the following 4-wk period, a high percentage $(29 \%)$ of individual plasma vitamin A values continued to be $<10 \mu \mathrm{g} / \mathrm{dl}$.

\section{DISCUSSION}

The etiology of BPD in newborn infants is considered to be multifactorial. Mechanical ventilation and supplemental $\mathrm{O}_{2}$ therapy for conditions such as HMD have been implicated as the major etiologic factors $(3,19-21)$. Congestive heart failure secondary to left-to-right shunting through a PDA (22), excessive intravenous fluid administration (23), and pulmonary interstitial air dissection (4) are suggested as contributing factors. Infants with HMD have epithelial necrosis of the lining cells of the terminal conducting airways, respiratory bronchioles, and alveolar ducts $(24,25)$. Vascular endothelial cells are also affected, with increased permeability and exudation of protein-rich fluid into the terminal air spaces. During the repair phase, the denuded epithelial surfaces are rapidly relined over a 2-3 day period with migrating new type II cells, which presumably differentiate from a residual stem cell population. The important function of vitamin A in preserving the structural and functional integrity of the epithelial cells could have a favorable effect in the healing process of preterm neonates recovering from HMD. In mechanically ventilated neonates, several factors such as barotrauma, airway infection, and chronic endotracheal intubation can cause extensive damage to the more proximal parts of the tracheobronchial tree and increase the risk of BPD. The potential role of vitamin $A$ in promoting normal reepithelialization of damaged airways could have a favorable effect in the healing process of preterm 
neonates susceptible to BPD and in avoiding the potentially harmful effects of squamous metaplasia in these infants. We therefore chose to evaluate sequentially the vitamin A status of a group of preterm neonates who developed clinical and radiographic evidence of BPD. A control group of neonates of similar birth weight and gestation without significant lung disease was studied for comparison.

The infants with BPD in this study are representative of infants with advanced BPD (26). Their characteristics include need for prolonged mechanical ventilation and supplemental $\mathrm{O}_{2}$ therapy, and significant morbidity resulting from a variety of complications such as pulmonary interstitial air dissection, symptomatic PDA, and recurrent airway infection.

Normal concentrations of vitamin A in blood range from 25$90 \mu \mathrm{g} / \mathrm{dl}$ in healthy adult humans. In children, including infants, a concentration $<20 \mu \mathrm{g} / \mathrm{dl}$ is generally considered to be suggestive of a suboptimal vitamin A status, and $<10 \mu \mathrm{g} / \mathrm{dl}$ is indicative of vitamin A deficiency (27). We have previously shown that a high percentage of preterm neonates have plasma vitamin A concentrations $<20 \mu \mathrm{g} / \mathrm{dl}$ in cord blood (9). The present study provides data on sequential determinations of plasma vitamin A concentration in preterm neonates in the early postnatal period.

In this study, during the 1st postnatal month, preterm neonates who progressed to develop BPD had significantly lower plasma vitamin A concentrations when compared to neonates without significant lung disease. Moreover, the vitamin A status of infants with BPD showed a biphasic pattern in the postnatal period. The initial phase was characterized by declining plasma vitamin A concentrations. The lowest plasma vitamin A concentrations were seen at 3-5 wk postnatal age and were markedly below the optimal level. The subsequent phase was characterized by a gradual rise in plasma vitamin A concentrations as seen in a majority of these infants. However, a high percentage of individual values of plasma vitamin A concentration in these infants continued to remain in the suboptimal range. These postnatal changes in plasma vitamin A concentration appear to be secondary to the varying amounts of vitamin $A$ in the diet and the varying modes of its provision. During the initial phase of declining plasma vitamin A concentrations, the average daily vitamin $A$ intake was $<700 \mathrm{IU} / \mathrm{kg} /$ day and the mode of feeding was predominantly intravenous. During the subsequent phase of increasing plasma vitamin A concentrations, the average daily vitamin $A$ intake was $>1500 \mathrm{IU} / \mathrm{kg} /$ day and the mode of feeding was predominantly by the gastrointestinal route. Other possible reasons for low plasma vitamin A concentrations in infants with BPD may include depleted liver reserves of vitamin A, suboptimal concentrations of plasma RBP, and increased tissue utilization of vitamin A. In contrast, the preterm infants without significant lung disease in our study did not show a substantial decline in their plasma vitamin A concentrations from the initial values. A higher vitamin $A$ intake and an earlier establishment of oral feeding in these infants may have prevented such a decline.

Animal studies $(1,2)$ of induced vitamin A deficiency have shown initial basal cell layer proliferation of the epithelium of the conducting airways followed by necrosis of the columnar ciliated and nonciliated lining cells. These cells are subsequently sloughed into the lumen, as the basal cells become confluent and differentiate into typical squamous layers. Infants dying with early BPD show a similar necrotizing bronchiolitis (3). Those dying at later stages of the disease may demonstrate basal cell layer proliferation and squamous metaplasia of conducting airway epithelium (3). The sequence of events of these changes due to vitamin A deficiency in animals and that associated with the development of BPD in human infants appear to be remarkably similar. In our study, we have shown an association between low plasma vitamin A concentrations and BPD in preterm neonates. It remains to be confirmed, however, whether the low plasma vitamin A concentrations are a cause of BPD or an effect of a deficient intake secondary to events associated with BPD. Further studies are needed to determine whether more efficient management of sick neonates with regard to their vitamin A nutrition and early achievement of vitamin A sufficiency could result in a decrease in the incidence and severity of BPD.

In summary, vitamin A status was assessed and compared in two groups of preterm neonates of comparable maturity, one who developed clinical and radiographic evidence of BPD, and the other who developed no significant lung disease. Our data show that infants who progress to develop BPD have suboptimal concentrations of plasma vitamin $A$ for extended periods of time postnatally, largely as a result of an inadequate vitamin A intake. The cause and effect relationship between vitamin A deficiency and BPD remains to be studied.

Acknowledgments. The authors gratefully acknowledge the expert technical assistance of Mark Hunt and Lucie Chytil.

\section{REFERENCES}

1. Wolbach SB, Howe PR 1925 Tissue changes following deprivation of fatsoluble vitamin A. J Exp Med 42:753-777

2. Wong YC, Buck RC 1971 An electron microscopic study of metaplasia of the rat tracheal epithelium in vitamin A deficiency. Lab Invest 24:55-66

3. Northway WH Jr, Rosan RC, Porter DY 1967 Pulmonary disease following respirator therapy of hyaline-membrane disease: bronchopulmonary dysplasia. N Engl J Med 276:357-368

4. Stahlman MT, Cheatham W, Gray ME 1979 The role of air dissection in bronchopulmonary dysplasia. J Pediatr 95:878-882

5. Wanner A 1977 Clinical aspects of mucociliary transport. Am Rev Respir Dis 116:73-125

6. Reid L, Jones R 1979 Bronchial mucosal cells. Fed Proc 38:191-196

7. Perkett E, Gray ME, Stahlman M 1981 Histochemical identification of chloride secreting cells in the fetal respiratory tract. In: Stern L, Salle B, Friis-Hansen $B$ (eds) Intensive Care in the Newborn III. Masson Publishing, New York, pp 275-278

8. Brandt RB, Mueller DG, Schroeder JR, Guyer KE, Kirkpatrick BV, Hutcher NE, Ehrlich FE 1978 Serum vitamin $A$ in premature and term neonates. $J$ Pediatr 92:101-104

9. Shenai JP, Chytil F, Jhaveri A, Stahlman MT 1981 Plasma vitamin A and retinol-binding protein in premature and term neonates. J Pediatr 99:302305

10. Bhatia J, Ziegler EE 1983 Retinol-binding protein and prealbumin in cord blood of term and preterm infants. Early Hum Dev 8:129-133

11. Shenai JP, Chytil F, Stahlman MT 1982 Liver vitamin A reserves of very lowbirth-weight (VLBW) neonates. Pediatr Res 16:177 (abstr).

12. Shenai JP, Stahlman MT, Chytil F 1981 Vitamin A delivery from parenteral alimentation solution. J Pediatr 99:661-663

13. Bancalari E, Abdenour GE, Feller R, Gannon J 1979 Bronchopulmonary dysplasia: clinical presentation. J Pediatr 95:819-823

14. Milner AD 1980 Bronchopulmonary dysplasia. Arch Dis Child 55:661-663

15. Edwards DK 1979 Radiographic aspects of bronchopulmonary dysplasia. J Pediatr 95:823-829

16. Stahlman MT 1981 Acute respiratory disorders in the newborn. In: Avery GB (ed) Neonatology, Pathophysiology and Management of the Newborn II. Lippincott, Philadelphia, pp 371-397

17. Thompson JN, Erdody P, Brien R, Murray TK 1971 Fluorometric determinations of vitamin $A$ in human blood and liver. Biochem Med 5:67-89

18. Cotton RB, Hickey D, Stahlman MT 1983 Management of premature infants with symptomatic patent ductus arteriosus. In: Stern L, Bard H, Friis-Hansen B (eds) Intensive Care in the Newborn IV. Masson Publishing, New York, pp 225-231

19. Bonikos DS, Bensch KG, Northway WH Jr 1976 Oxygen toxicity in the newborn: the effect of chronic continuous 100 percent oxygen exposure on the lungs of newborn mice. Am J Pathol 85:623-650

20. Stern L 1979 The role of respirators in the etiology and pathogenesis of bronchopulmonary dysplasia. J Pediatr 95:867-869

21. Boat TF 1979 Studies of oxygen toxicity in cultured human neonatal respiratory epithelium. J Pediatr 95:916-919

22. Brown ER 1979 Increased risk of bronchopulmonary dysplasia in infants with patent ductus arteriosus. J Pediatr 95:865-869

23. Brown ER, Stark A, Sosenko I, Lawson EE, Avery ME 1978 Bronchopulmonary dysplasia: Possible relationship to pulmonary edema. J Pediatr 92:982984

24. Singer DB 1984 Morphology of hyaline membrane disease and its pulmonary sequelae. In: Stern L (ed) Hyaline Membrane Disease: Pathogenesis and Pathophysiology. Grune and Stratton, Orlando, pp 63-96

25. Stahlman MT 1984 Chronic respirator lung disease following hyaline membrane disease. In: Stern L (ed) Neonatal Medicine. Masson Publishing, New York, pp 101-104

26. Stahlman MT 1979 Clinical description of bronchopulmonary dysplasia. J Pediatr 95:829-834

27. Pitt GAJ 1981 The assessment of vitamin A status. Proc Nutr Soc 40:173-178 